\title{
Article \\ Spatial Network Structure of China's Provincial-Scale Tourism Eco-Efficiency: A Social Network Analysis
}

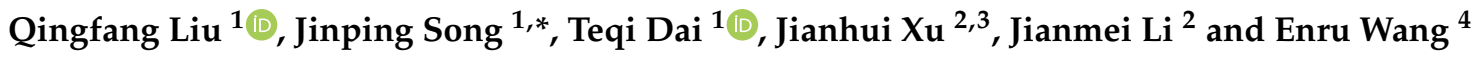 \\ 1 Faculty of Geographical Science, Beijing Normal University, Beijing 100875, China; \\ m13155029850@163.com (Q.L.); daiteqi@bnu.edu.cn (T.D.) \\ 2 School of Geographic Information and Tourism, Chuzhou University, Chuzhou 239099, China; \\ xjhgx@chzu.edu.cn (J.X.); lijianmei@126.com (J.L.) \\ 3 Finnish Meteorological Institute, FI-00101 Helsinki, Finland \\ 4 Department of Geography \& Geographic Information Science, University of North Dakota, \\ Grand Forks, ND 58202, USA; enru.wang@email.und.edu \\ * Correspondence: jinpingsong@163.com
}

check for updates

Citation: Liu, Q.; Song, J.; Dai, T.; Xu, J.; Li, J.; Wang, E. Spatial Network Structure of China's Provincial-Scale Tourism Eco-Efficiency: A Social Network Analysis. Energies 2022, 15, 1324. https://doi.org/10.3390/ en15041324

Academic Editors: Roberto Alonso González Lezcano, Francesco Nocera and Rosa Giuseppina Caponetto

Received: 18 January 2022

Accepted: 8 February 2022

Published: 11 February 2022

Publisher's Note: MDPI stays neutral with regard to jurisdictional claims in published maps and institutional affiliations.

Copyright: (c) 2022 by the authors. Licensee MDPI, Basel, Switzerland. This article is an open access article distributed under the terms and conditions of the Creative Commons Attribution (CC BY) license (https:// creativecommons.org/licenses/by/ $4.0 /)$.

\begin{abstract}
While tourism eco-efficiency has been analyzed actively within tourism research, there is an extant dearth of research on the spatial network structure of provincial-scale tourism eco-efficiency. The Super-SBM was used to evaluate the tourism eco-efficiency of 30 provinces (excluding Tibet, Hong Kong, Macao and Taiwan). Then, social network analysis was employed to examine the evolution characteristics regarding the spatial network structure of tourism eco-efficiency. The main results are shown as follows. Firstly, tourism eco-efficiency of more than two thirds' provinces witnessed an increasing trend. Secondly, the spatial network structure of tourism eco-efficiency was still loose and unstable during the sample period. Thirdly, there existed the multidimensional nested and fused spatial factions and condensed subsets in the spatial network structure of tourism eco-efficiency. However, there was still a lack of low-carbon tourism cooperation among second or third sub-groups. These conclusions can provide references for policymakers who expect to reduce carbon emissions from the tourism industry and to achieve sustainable tourism development.
\end{abstract}

Keywords: low-carbon tourism; tourism eco-efficiency; spatial network correlation; Super-SBM; social network analysis

\section{Introduction}

Tourism has solidified its role as the strategic-pillar industry in China [1], accounting for $6.69 \%$ of the total gross domestic product (GDP) in 2019. For a long time, tourism has been regarded as an industry with low-carbon and environmental protections [2]. Therefore, adequate attention is not paid to the pollution brought by tourism industry in China. With the expansion and improvement of the tourism economy, the negative environment impacts of the tourism industry have gradually been exposed [3]. The Fourteenth Five Year Plan, issued by the central government in March 2021, emphasized the high-quality development is the main direction of the tourism industry in the next five years. Tourism eco-efficiency is defined as creating more economic value in tourism products and service, while eliminating negative environmental effects and reducing resource consumption [4-6]. The improvement of tourism eco-efficiency cannot only be in accordance with the goal of carbon emission peaking and carbon neutrality (Two Carbon) but also promote the high-quality development of tourism industry [7].

With the exposure of the negative impacts of tourism development on ecological environment, quite a few scholars have gradually begun to concentrate how to achieve low-carbon development in tourist destinations. Moreover, the Sustainable Tourism Development Action Strategy (STDAS) put forward the concept of sustainable tourism, and pointed out that both ecological environment and economic benefit should be taken into 
consideration [7]. Based on the core principles of sustainable tourism, Gössling, Peeters, Ceron, Dubois, Patterson and Richardson [6], calculating the carbon emissions from the tourism industry, put forward the concept of tourism eco-efficiency. Since then, it has triggered a huge wave in academic tourism circle. Extant assessment methods are divided into two types, namely, the single indicator method, and the model method [4]. With regard to the single indicator method, tourism eco-efficiency can be expressed by the ratio of tourism economic benefit to the environmental effect [8]. During the application of the single indicator method, the tourism receipt and the carbon dioxide emission from tourism industry were defined as the tourism input and the environmental effects, respectively, by Perch-Nielsen, et al. [9] Additionally, some scholars regarded tourism-related carbon footprint as the environmental effect of tourism [10-12]. However, the superior rational is not obtained by the single indicator method; meanwhile, this method is suitable for a single object or item. Thus, the single indicator method may not provide more targeted implications for tourist destination management (TDM) [2]. In terms of the model method, constructing the index system of input-output is a prerequisite for evaluating tourism eco-efficiency; the choice of evaluation models can reduce error, and make the results more scientific [4]. The index system of input-output mainly contains capital, labor, energy consumption, tourism receipt and the environmental effects [4,13]. Moreover, the non-convex metafrontier DEA-based model, Super-DEA model, and Super-EBM model are used to take into consideration the undesired output, such as carbon emissions from the tourism industry, tourism solid waste discharge, and tourism wastewater discharge $[2,13,14]$. In addition, some scholars have also investigated the factors driving the evolution of tourism eco-efficiency. The main factors include the level of tourism economy [7], technological innovation [15], industrial structure of tourism [16] and environmental regulation [17].

With the improvement of market mechanism and regional integration, the production factors such as talent, technology, and capital of the low-carbon tourism development flow among various areas, resulting in tourism eco-efficiency in different areas, has grown more connected [18]. Due to the implementation of eco-environmental policies, there is more communication and cooperation regarding tourism sustainable development. Therefore, technologies relevant to low-carbon tourism and the experience of managers are exchanged among various regions, resulting in the formation of a spatial network structure of tourism eco-efficiency [2]. What's more, exploring the spatial network structure of tourism eco-efficiency can provide reference for the cooperation and communication of sustainable tourism development. Some scholars have explored the spatiotemporal evolution characteristics regarding tourism eco-efficiency by adopting exploratory spatial data analysis (ESDA) based on the attribute data $[15-17,19,20]$. However, scholars failed to devote to enough attentions to the spatial network structure of tourism eco-efficiency based on the relational data. In particular, the roles that various provinces play in the spatial network structure of tourism eco-efficiency have seldom been studied.

In order to fill this gap, taking 30 provinces in China as the case studies, this study explored the evolution characteristics regarding spatial network structure of tourism ecoefficiency. To our best knowledge, this study is among the first to explore the spatial network structure of provincial-scale tourism eco-efficiency. Our research makes three contributions to the extant literature on tourism eco-efficiency. First, this study casts new light on our understanding of the spatial connection and spatial spillover of tourism eco-efficiency from the relational data rather than attribute data. Secondly, the previous literature mainly concentrated on the evaluation of tourism eco-efficiency, whereas this study enriched and broadened research topics such as spatial characteristics. Thirdly, our research sought to advance original methodological and empirical contributions. To be more specific, this study established a comprehensive research framework regarding the spatial network structure of tourism eco-efficiency. Although the example is limited to China, this research framework is, to a certain extent, universalizable.

The rest of this study is structured as follows. Section 2 introduced the main research method, the index system and the data source. The empirical results were presented in 
Section 3, in which this study evaluated the tourism eco-efficiency and explored the evolution characteristics regarding the spatial network structure of tourism eco-efficiency. The discussion and conclusions were presented in Section 4, in which this study discussed the empirical results, summarized the literature contributions, and provided recommendations for tourist destination management.

\section{Materials and Methodology}

\subsection{Method}

\subsubsection{Super-SBM}

Data envelopment analysis (DEA) is a model that evaluates multiple decision units with similar inputs and outputs [21]. However, there are two main shortcomings in the traditional DEA morel. First, the slack variables may affect the accuracy of the evaluation results. Second, there solely exists expected output, and the undesirable output is not fully taken into account. In order to make up the for above-mentioned deficiencies, Tone [22] proposed the slack-based model (SBM) based on the undesirable output, which not only takes into consideration the issue of slack, but also includes undesirable output. There is no doubt that the modifications of the model can make the evaluation more accurate. Nevertheless, when the SBM is employed to assess the efficiency of several decision-making units (DMUs), it is easy to generate the phenomenon wherein the efficiency values of DMUs all reach the optimal frontier production surface [23]. In other words, the efficiency values of multiple DMUs are 1, which makes the comparison of DMUs' efficiency impossible. Considering this issue, Tone [24] put forward the Super-SBM model based on the traditional SBM. The formula of Super-SBM is as follows.

$$
\left\{\begin{array}{l}
\text { Min }=\frac{\frac{1}{m} \sum_{i=1}^{m}\left(\bar{x} / x_{i k}\right)}{\frac{1}{\overline{11}+r^{2}}\left(\sum_{s=1}^{r 1} \overline{y^{d}} / y_{s k}^{d}+\sum_{q=1}^{r 2} \overline{y^{u}} / y_{q k}^{u}\right)} \\
\bar{x} \geq \sum_{j=1, \neq k}^{n} x_{i j} \lambda_{j} ; \overline{y^{d}} \leq \sum_{j=1, \neq k}^{n} y_{s j}^{d} \lambda_{j} ; \overline{y^{d}} \geq \sum_{j=1, \neq k}^{n} y_{q j}^{d} \lambda_{j} \\
\bar{x} \geq x_{k} ; \overline{y^{d}} \leq y_{k}^{d} ; \overline{y^{u}} \geq y_{k}^{u} ; \lambda_{j} \geq 0, i=1,2, \ldots, m \\
j=1,2, \ldots, n ; j=1,2, \ldots, n ; q=1,2, \ldots, r_{2}
\end{array}\right.
$$

where, $\rho$ is the tourism eco-efficiency; $x, y^{d}$ and $y^{u}$ are input, expected output and undesirable output, respectively. $m, r_{1}$, and $r_{2}$ are the quantities of inputs, expected outputs and undesirable outputs, respectively. A value of tourism eco-efficiency greater than or equal to 1 indicates that the tourism eco-efficiency is in an effective state; otherwise, it is in an invalid state.

\subsubsection{Modified Gravity Model}

A province is a point in the spatial network structure of tourism eco-efficiency, and the spatial connection of tourism eco-efficiency among provinces is the line [25]. At present, the vecto autoregressive (VAR) model, and the modified gravity model are universally used to establish the spatial correlation matrix of tourism eco-efficiency. Given that the sensibility regarding the choice of lag order may reduce the accuracy of examining the network structure characteristics [26], the modified gravity model has been universally applied to construct the spatial correlation matrix. More importantly, this model can take consideration into the "quality" and "distance", and reflect the evolution characteristics regarding the spatial network structure [27]. Based on the above-mentioned advantages, this study applied the modified gravity model. The formula is as follows.

$$
F_{i j}=K_{i j} \frac{E_{i} \cdot E_{j}}{D_{i j}{ }^{2}}, K_{i j}=\frac{E_{i}}{E_{i}+E_{j}}
$$


where $F_{i j}$ denotes the gravity between province $i$ and province $j . E_{i}$ and $E_{j}$ represent the tourism eco-efficiency in province $i$ and province $j$, respectively. $D_{i j}$ represents the distance between province $i$ and province $j$, which is represented by the shortest straightline distance among two provincial capitals [25]. $K_{i j}$ is the correction coefficient. Generally speaking, provinces with high tourism eco-efficiency possess a stronger radiation effect on provinces than that of provinces with low tourism eco-efficiency, through radiation of tourism low-carbon technology and spillovers of tourism low-carbon information [2]. In this study, $K_{i j}$ is calculated by the proportion of tourism eco-efficiency of province $i$ in the sum of tourism eco-efficiency of province $i$ and province $j$.

\subsubsection{Social Network Analysis}

Social network analysis (SNA), an interdisciplinary research method, aims to describe the relationship among members in a network and the influence of different relationship patterns on the characteristics regarding network structure based on graph theory and algebra $[1,28]$. Due to the advantages of intuitive graphics and accurate characterization, the application of SNA has been gradually expanded from sociology to economics, management, psychology, geography and other disciplines $[27,29,30]$. This study mainly adopted the SNA to explore the overall and individual characteristics regarding spatial network structure of tourism eco-efficiency in China and to reveal the actual or potential relationship between provinces. The relevant formulas can be seen in Table 1.

Table 1. Formulas of indicators regarding social network analysis.

\begin{tabular}{|c|c|c|c|}
\hline Index & Formula & Number & Explanation of Formula \\
\hline Network density & $D=\frac{L}{N \times(N-1)}$ & (3) & $\begin{array}{c}\text { Where } D \text { is the network density, } L \text { is the actual } \\
\text { relationship number, and } N \text { is the number of } \\
\text { research areas. }\end{array}$ \\
\hline Network hierarchy & $H=1-\frac{K}{\max (K)}$ & $(4)$ & $\begin{array}{l}\text { Where } H \text { is the network hierarchy, } K \text { is the } \\
\text { symmetric reachable points, and } \max (K) \text { is the } \\
\text { maximum possible point logarithm. }\end{array}$ \\
\hline Network efficiency & $E=1-\frac{M}{\max (M)}$ & (5) & $\begin{array}{c}\text { Where } E \text { is the network efficiency, } M \text { is the number } \\
\text { of redundant lines, and } \max (M) \text { is the maximum } \\
\text { number of possible redundant lines. }\end{array}$ \\
\hline Clustering coefficient & $C_{i}=\frac{2 e_{i}}{k_{i}\left(k_{i}-1\right)}$ & (6) & $\begin{array}{c}\text { Where } C_{i} \text { is the clustering coefficient, } e_{i} \text { represents } \\
\text { the number of edges between } k \text { neighbors of } \\
\text { province } I, k_{i} \text { is the number of edges of node } i .\end{array}$ \\
\hline Average path length & $L=\frac{1}{1 / 2 N(N-1)} \sum_{i>i} d_{i j}$ & (7) & $\begin{array}{l}\text { Where } N \text { is the total of network nodes, } d_{i j} \text { is distance } \\
\text { between province } i \text { and province } j .\end{array}$ \\
\hline Degree centrality & $D e=\frac{n}{N-1}$ & (8) & $\begin{array}{c}\text { Where De is the point centrality, } n \text { is the number of } \\
\text { nodes connected with the province, and } N \text { is the } \\
\text { maximum number of nodes connected with } \\
\text { the province. }\end{array}$ \\
\hline Betweenness centrality & $C b_{i}=\frac{2 \sum_{i}^{n} \sum_{j}^{n} b_{i j}(l)}{N^{2}-3 N+2}, i \neq j \neq l, i<j$ & (9) & $\begin{array}{l}\text { Where } C b_{i} \text { is betweenness centrality; } b_{i j} \text { is the } \\
\text { number of the shortcuts between city } i \text { and city } j \text {; } \\
\text { and } b_{i j}(l) \text { represents the number of shortcuts } \\
\text { between province } i \text { and province } j \text {. }\end{array}$ \\
\hline Closeness centrality & $C_{A P i}^{-1}=\sum_{i=1}^{n} d_{i j}$ & $(10)$ & $\begin{array}{l}\text { Where } C_{A P i}^{-1} \text { is closeness centrality; and } d_{i j} \text { is the } \\
\text { shortest distance between province } i \text { and province } j \text {. }\end{array}$ \\
\hline
\end{tabular}

(1) The overall network structure characteristics. The overall network structure characteristics are mainly reflected by six indexes, namely, network density, network connectedness, network hierarchy, network efficiency, clustering coefficient and average path length. Network density and network connectedness mainly reflect the density degree of spatial network structure. The higher the network density is, the more connectedness there is, and the closer the spatial network structure is. The network hierarchy mainly assess the asymmetric accessibility of network individual. The higher the network hierarchy, the 
more rigid the network structure, and more provinces play the role of edge in the spatial network structure. Network efficiency mainly reflects the connection efficiency among nodes in the spatial network structure. If the network efficiency is lower, there will be more spillover channels among various provinces, and the more stable the network structure is. The clustering coefficient and the average path length are used to mirror the characteristics of "small-world" regarding the spatial network structure [31], among which, the clustering coefficient mainly represents the cohesion of the spatial network structure. The higher the clustering coefficient is, the more frequent the network connections are. The average path length can indicate the distance between nodes.

(2) The individual network structure characteristics. The individual network structure characteristics are mainly reflected by three indexes, namely degree centrality, betweenness centrality and closeness centrality. Specifically, the point centrality reflects the central position of the node in the network structure. The greater power in the network structure, and the more prominent the central position of the node in the network structure. Betweenness centrality mirrors the degree to which nodes control the connections among other nodes. The higher the betweenness centrality, the greater the priority and control of the node. Closeness centrality reflects the ability a node to be controlled by other nodes. The greater closeness centrality, the more direct spatial associations among nodes, and the easier it is for the node to play the role of the center.

(3) Network cohesive sub-groups analysis. Cohesive sub-groups can explain the substructure within a group, which is a broad concept of sub-group [28]. Nodes in a subgroup possess relatively strong, relatively close and relatively direct relationships, whose fundamental purpose is to reveal the actual or potential relationship between nodes [32].

\subsection{Index System Selection}

This study regards capital, labor and energy as the tourism input indicators. Land is one of the most basis production factors in economic activities, but it is not a decisive factor affecting the intensive or extensive management of tourism industry in the process of tourism economic development [33]. More seriously, there is a dearth of the dataset on the number of tourism land-use [1]. Therefore, the land is not seen as the basis input in this study. Capital input has a significant influence on the development pathway to a certain extent, thus, playing an indispensable role in the low-carbon tourism development. In this study, the total of fixed asset investment regarding tourist attractions, travel agencies and star-hotels is used to represent the level of tourism capital investment [28]. Additionally, tourism industry is regarded as a labor-intensive industry with significant employment attributes. In this study, the number of tourism employees is used to represent the labor input of tourism [34]. Tourism energy input is of great importance in evaluating tourism eco-efficiency; this study selects tourism energy consumption to represent tourism energy input [13].

With respect to the expected output index, the total tourism revenue is the direct embodiment of economic benefits from tourism. Moreover, the total number of tourists can better reflect the spillover effect of the tourism industry [35]. In terms of undesired output, this study adopts carbon emissions from the tourism industry to reflect the negative impact of tourism-related economic development on the ecological environment $[7,13]$.

\subsection{Data Source}

In this study, 30 provinces (excluding Tibet, Hong Kong, Macao and Taiwan) were taken as the case studies. The data on inbound tourism revenue, inbound tourist arrival, and fixed asset investment in the tourism industry were mainly received from the China Statistical Yearbook (2001 2018) and China Tourism Statistical Yearbook (2001 2018). Domestic tourism revenue and domestic tourist arrival were mainly taken from the statistical yearbooks of 11 provinces during the period of 2001 2018. Quite a few data were supplemented and improved by the statistical bulletins of national economic and social development of each province. With regard to carbon emissions and energy consumption, 
this study adopted the "bottom-up" method, including decomposition and summation based on determining the key areas, overall tourism energy consumption and carbon emissions [36,37]. The specific calculation process was played in Appendix A. The data involved in the calculation of energy consumption and carbon emissions from the tourism industry were mainly received from the China Transport Statistical Yearbook (2001 2018) and the China Energy Statistical Yearbook (2001 2018). A part of the data is collected from the Tourism Sample Survey Data (2001 2018) and the Statistical Bulletin of National Economic and Social Development. Additionally, in order to avoid the interference of price factors on the empirical results, the data of income nature is adjusted, with year 2000 as the baseline period.

\section{Results}

\subsection{Measurement of Tourism Eco-Efficiency}

China's tourism eco-efficiency, shown in Table 2, witnessed a fluctuating growth trend during the study period, which increased from 0.441 in 2000 to 0.525 in 2017, with an average annual growth rate of $1.1 \%$. This indicated that tourism-related economic development in China still relied on resources and harmed the environment; thus, there is tremendous room for progress in low-carbon tourism development. According to the partition criterion, formulated by the National Bureau of Statistics in 2011, 30 provinces were divided into four areas, namely Eastern area, Central area, Western area, and Northeastern area. From the perspective of the sub-area, the tourism eco-efficiency in the Eastern, Central, Western and Northeastern areas all showed a fluctuating growth trend, with the largest growth rate $(32.70 \%)$, and the smallest growth rate $(14.31 \%)$, respectively (Figure 1$)$. The order of the spatial heterogeneity distribution pattern regarding the mean of tourism ecoefficiency by area was Eastern (0.740), Northeastern (0.440), Central (0.429) and Western (0.217) during the period of 2000 2017. At the provincial level, except for Beijing, Tianjin, Liaoning, Henan, Hunan, Chongqing, Sichuan, Qinghai and Ningxia, tourism eco-efficiency of the remaining 21 provinces experienced varying degrees of increase during the study period; the largest increase was in Jilin Province (197.18\%); the largest decrease was in Qinghai Province (43.33\%), indicating that, due to the differences in the input of the material elements of the tourism economy, there was great spatial heterogeneity in the tourism eco-efficiency among these provincial areas in China.

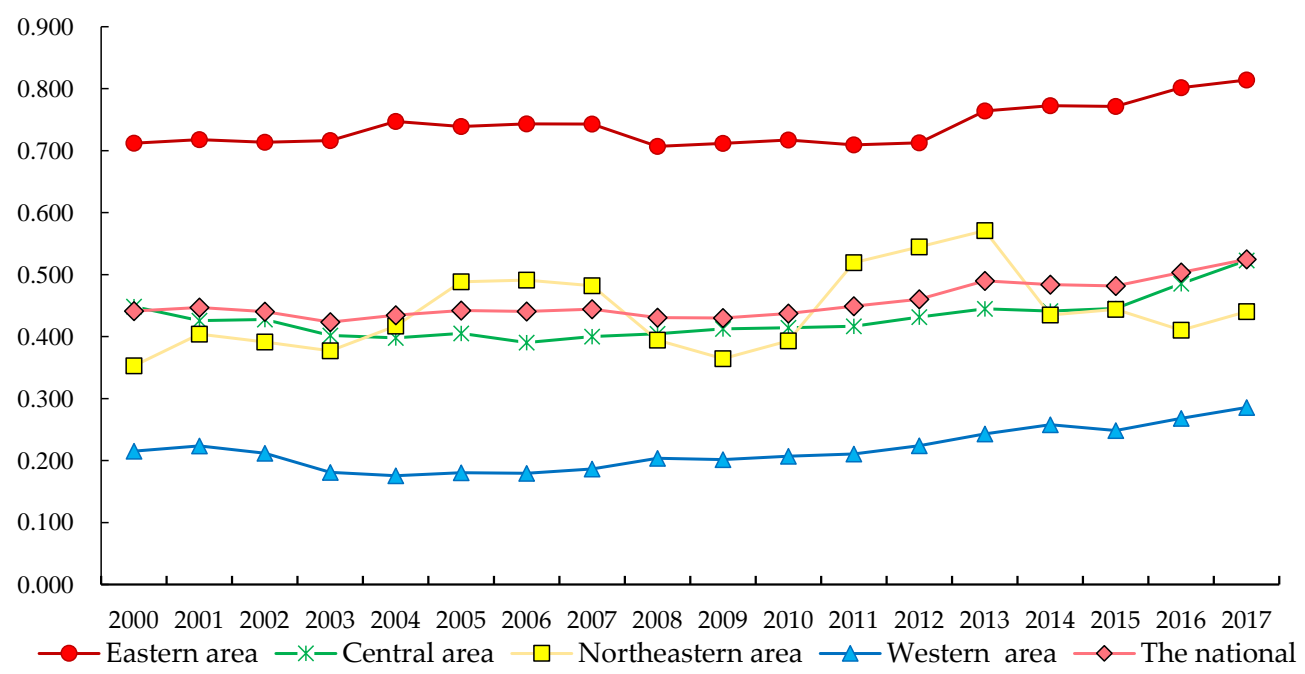

Figure 1. The evolution trend of tourism eco-efficiency in China and four sub-regions from 2000 to 2017. Eastern area includes Beijing, Tianjin, Hebei, Shanghai, Jiangsu, Zhejiang, Fujian, Shandong, Guangdong, and Hainan. Central area consists of Shanxi, Jiangxi, Anhui, Henan, Hubei, Hunan. Western area includes Inner Monglia, Guangxi, Chongqing, Sichuang, Guizhou, Yunan, Shannxi, Gansu, Qinghai, Ningxia, and Xinjiang. Northeastern area includes Liaoning, Jilin, and Heilongjiang. 
Table 2. Tourism eco-efficiency of 30 provinces from 2000 to 2017.

\begin{tabular}{|c|c|c|c|c|c|c|c|c|}
\hline Province & 2000 & 2003 & 2006 & 2009 & 2012 & 2015 & 2017 & Mean \\
\hline Beijing & 0.440 & 0.523 & 0.577 & 0.504 & 0.419 & 0.397 & 0.421 & 0.469 \\
\hline Tianjin & 1.670 & 1.749 & 1.763 & 1.517 & 1.460 & 1.461 & 1.548 & 1.595 \\
\hline Hebei & 0.380 & 0.297 & 0.296 & 0.328 & 0.380 & 0.423 & 0.502 & 0.362 \\
\hline Shanxi & 0.221 & 0.184 & 0.175 & 0.242 & 0.326 & 0.400 & 0.551 & 0.277 \\
\hline Inner Monglia & 0.295 & 0.287 & 0.296 & 0.344 & 0.434 & 0.591 & 0.621 & 0.399 \\
\hline Liaoning & 0.628 & 0.732 & 1.016 & 0.583 & 1.031 & 0.631 & 0.608 & 0.783 \\
\hline Jilin & 0.140 & 0.156 & 0.200 & 0.233 & 0.299 & 0.415 & 0.415 & 0.256 \\
\hline Heilongjiang & 0.291 & 0.244 & 0.257 & 0.278 & 0.304 & 0.286 & 0.298 & 0.282 \\
\hline Shanghai & 1.164 & 1.139 & 1.139 & 1.189 & 1.131 & 1.214 & 1.156 & 1.174 \\
\hline Jiangsu & 1.052 & 1.069 & 1.095 & 1.112 & 1.119 & 1.137 & 1.139 & 1.105 \\
\hline Zhejiang & 0.486 & 0.493 & 0.609 & 0.564 & 0.662 & 1.031 & 1.160 & 0.707 \\
\hline Anhui & 0.215 & 0.204 & 0.198 & 0.224 & 0.217 & 0.245 & 0.320 & 0.229 \\
\hline Fujian & 0.262 & 0.243 & 0.277 & 0.315 & 0.283 & 0.298 & 0.315 & 0.284 \\
\hline Jiangxi & 0.304 & 0.262 & 0.253 & 0.293 & 0.338 & 0.326 & 0.433 & 0.308 \\
\hline Shandong & 0.390 & 0.356 & 0.384 & 0.343 & 0.369 & 0.449 & 0.579 & 0.407 \\
\hline Henan & 1.394 & 1.355 & 1.322 & 1.267 & 1.218 & 1.217 & 1.219 & 1.283 \\
\hline Hubei & 0.269 & 0.198 & 0.222 & 0.260 & 0.286 & 0.293 & 0.370 & 0.267 \\
\hline Hunan & 0.289 & 0.209 & 0.173 & 0.188 & 0.204 & 0.192 & 0.245 & 0.209 \\
\hline Guangdong & 1.122 & 1.151 & 1.149 & 1.113 & 1.132 & 1.129 & 1.132 & 1.134 \\
\hline Guangxi & 0.130 & 0.121 & 0.138 & 0.171 & 0.219 & 0.292 & 0.369 & 0.205 \\
\hline Hainan & 0.153 & 0.143 & 0.144 & 0.134 & 0.170 & 0.176 & 0.189 & 0.158 \\
\hline Chongqing & 0.368 & 0.282 & 0.294 & 0.283 & 0.268 & 0.276 & 0.316 & 0.298 \\
\hline Sichuan & 0.198 & 0.142 & 0.143 & 0.160 & 0.177 & 0.167 & 0.170 & 0.166 \\
\hline Guizhou & 0.271 & 0.268 & 0.255 & 0.336 & 0.366 & 0.383 & 0.406 & 0.328 \\
\hline Yunnan & 0.249 & 0.179 & 0.162 & 0.215 & 0.255 & 0.253 & 0.327 & 0.227 \\
\hline Shaanxi & 0.286 & 0.244 & 0.229 & 0.258 & 0.272 & 0.258 & 0.336 & 0.264 \\
\hline Gansu & 0.194 & 0.151 & 0.153 & 0.141 & 0.157 & 0.177 & 0.221 & 0.166 \\
\hline Qinghai & 0.139 & 0.102 & 0.097 & 0.101 & 0.092 & 0.083 & 0.079 & 0.100 \\
\hline Ningxia & 0.079 & 0.071 & 0.066 & 0.058 & 0.054 & 0.055 & 0.053 & 0.062 \\
\hline Xinjiang & 0.161 & 0.146 & 0.140 & 0.150 & 0.170 & 0.200 & 0.245 & 0.171 \\
\hline Mean & 0.441 & 0.423 & 0.441 & 0.430 & 0.460 & 0.482 & 0.525 & 0.456 \\
\hline
\end{tabular}

Notes: Due to the length limitation, the results of 2000, 2003, 2006, 2009, 2012, 2015, and 2017 are only represented in Table 2.

\subsection{The Spatial Network Structures \\ 3.2.1. Overall Network Characteristics}

In this study, ArcGIS10.3 software was used to draw the network structure of China's provincial-scale tourism eco-efficiency, which can reflect the overall network structure characteristics of tourism eco-efficiency in China. Figure 2 showed that with the implementation of the ecological civilization strategy and the high-quality development strategy, the cooperation among different provinces in promoting the transformation of the tourism development mode has been deepening. Therefore, the spatial network structure of tourism eco-efficiency was complex and dense. The overall network structure of China's tourism eco-efficiency, shown in Figure 2, was relatively loose during the study period. The average number of network relationships in each province was 107; the average network density was 0.123 ; the average clustering coefficient was 0.417 , and the average path length was 2.98. Low network agglomeration, connectivity, and closeness were not only conducive to the diffusion and spillovers of tourism low-carbon production factors, such as technologies, talents and capital among provinces, but also affected the stability of the spatial network structure of tourism eco-efficiency. 

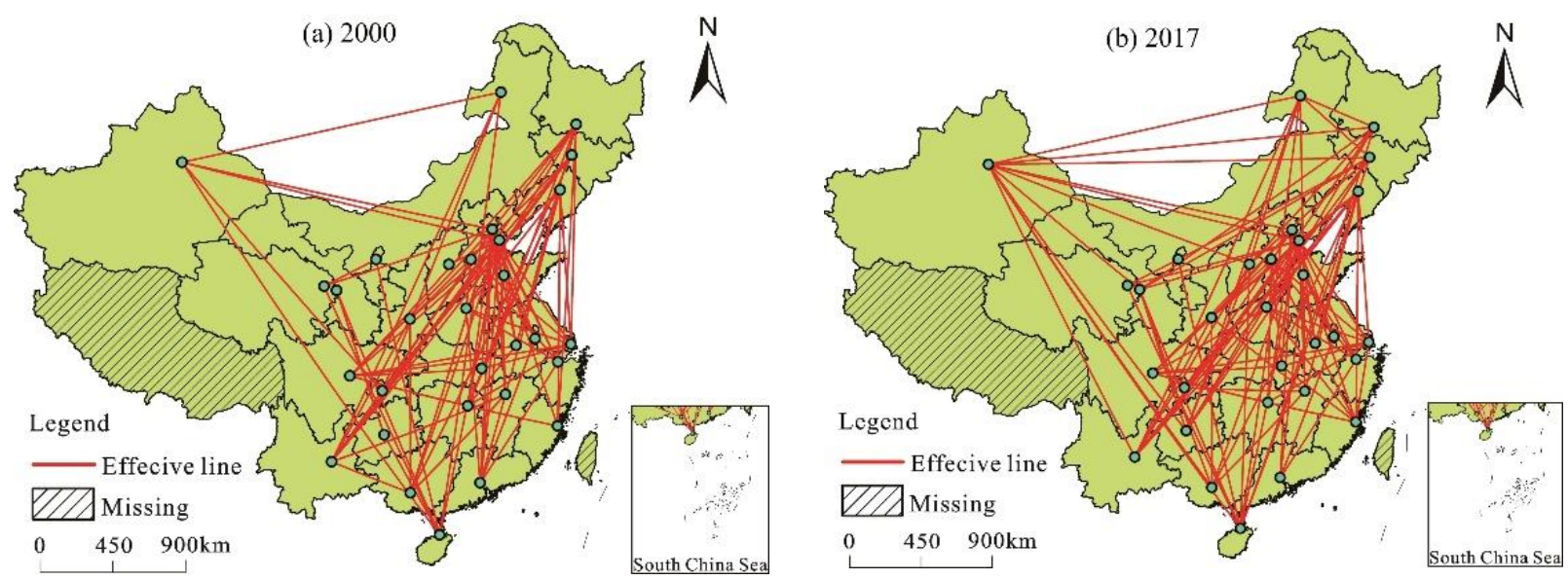

Figure 2. Spatial network structure of tourism eco-efficiency in year 2000 (a), and 2017 (b), China.

In terms of the evolution trend, the network density, and the number of network relationships, were both increasing slowly in the fluctuation; however, the increase degree was still small, which indicated that the scale, level and standard of low-carbon tourism cooperation among these provinces were still low (Figure 3). It was noteworthy that the clustering coefficient witnessed a slight downward trend, while the average path length experienced a slight upward trend, revealing that the connectivity of the tourism ecoefficiency transmission and the cohesion of the overall network structure among provinces have decreased. Additionally, this highlights that the low-carbon technology between provinces used to promote low-carbon tourism development still faces obstacles and constraints, such as administrative boundaries.
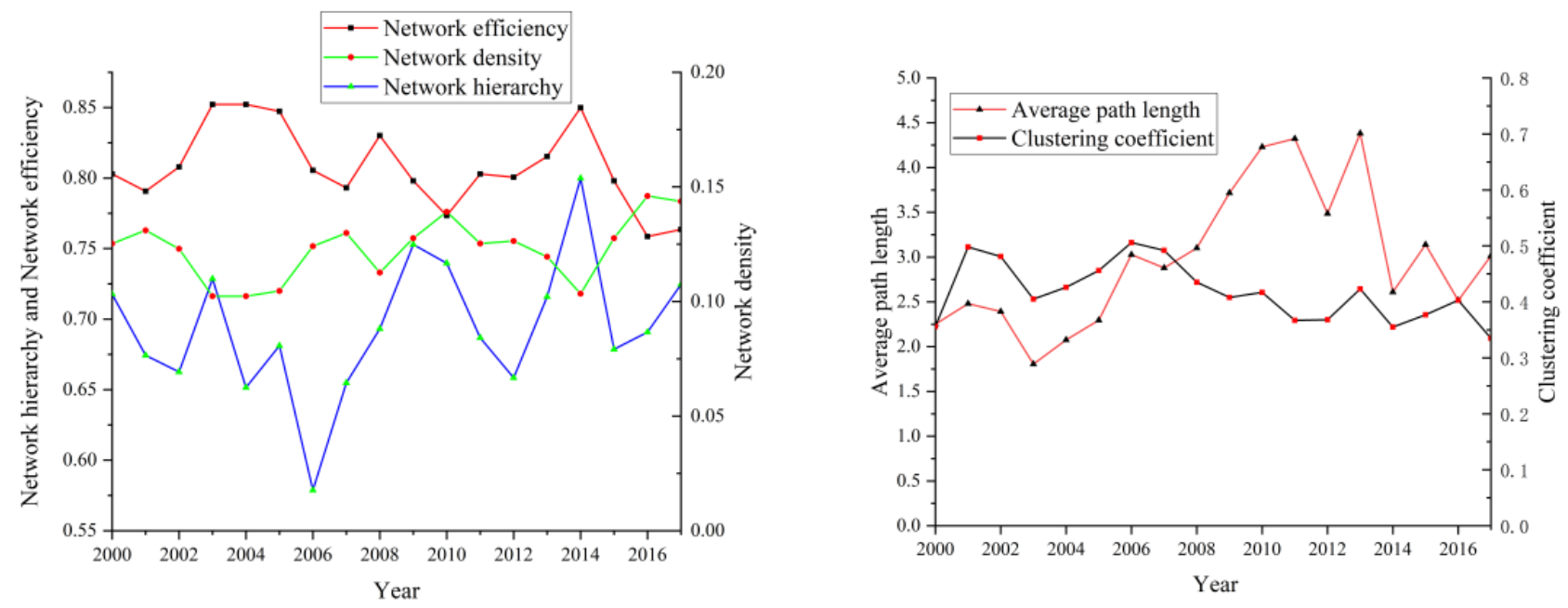

Figure 3. Overall spatial network structure of tourism eco-efficiency.

Figure 3 revealed that the network hierarchy regarding spatial network structure of China's provincial-scale tourism eco-efficiency increased from 0.718 in 2000 to 0.725 in 2017; the network hierarchy always remained above the value of 0.57 , indicating that there was a hierarchical network structure in the spillover effect of tourism eco-efficiency among provinces and that this hierarchical structure was becoming increasingly intense. Additionally, the spatial equilibrium of tourism eco-efficiency in each province was relatively poor; the internal environment in which the spill occurred was as terrible as the radiation.

On the contrary, while the network efficiency experienced a downward trend in the fluctuation, decreasing from 0.803 in 2000 to 0.764 in 2017, which revealed that the connectivity of network structure of tourism eco-efficiency has increased, the routes of 
tourism ecological resource elements spillovers among provinces has been raised, and the stability of spatial correlation has been improved. However, there was also a risk that with the increase of redundant cables, the transmission efficiency of the network structure would be reduced. Therefore, maintaining reasonable network efficiency can optimize the allocation of network resources.

\subsubsection{Individual Network Characteristics}

In this study, three indexes, i.e., degree centrality, betweenness centrality and closeness centrality, were used to analyze the characteristics regarding individual network structure of tourism eco-efficiency. Furthermore, the spatio-temporal evolution characteristics of the above-mentioned three indicators, adopting the ArcGIS10.2 software, were visually played by the inverse distance weight (IDW) method (Figure 4).
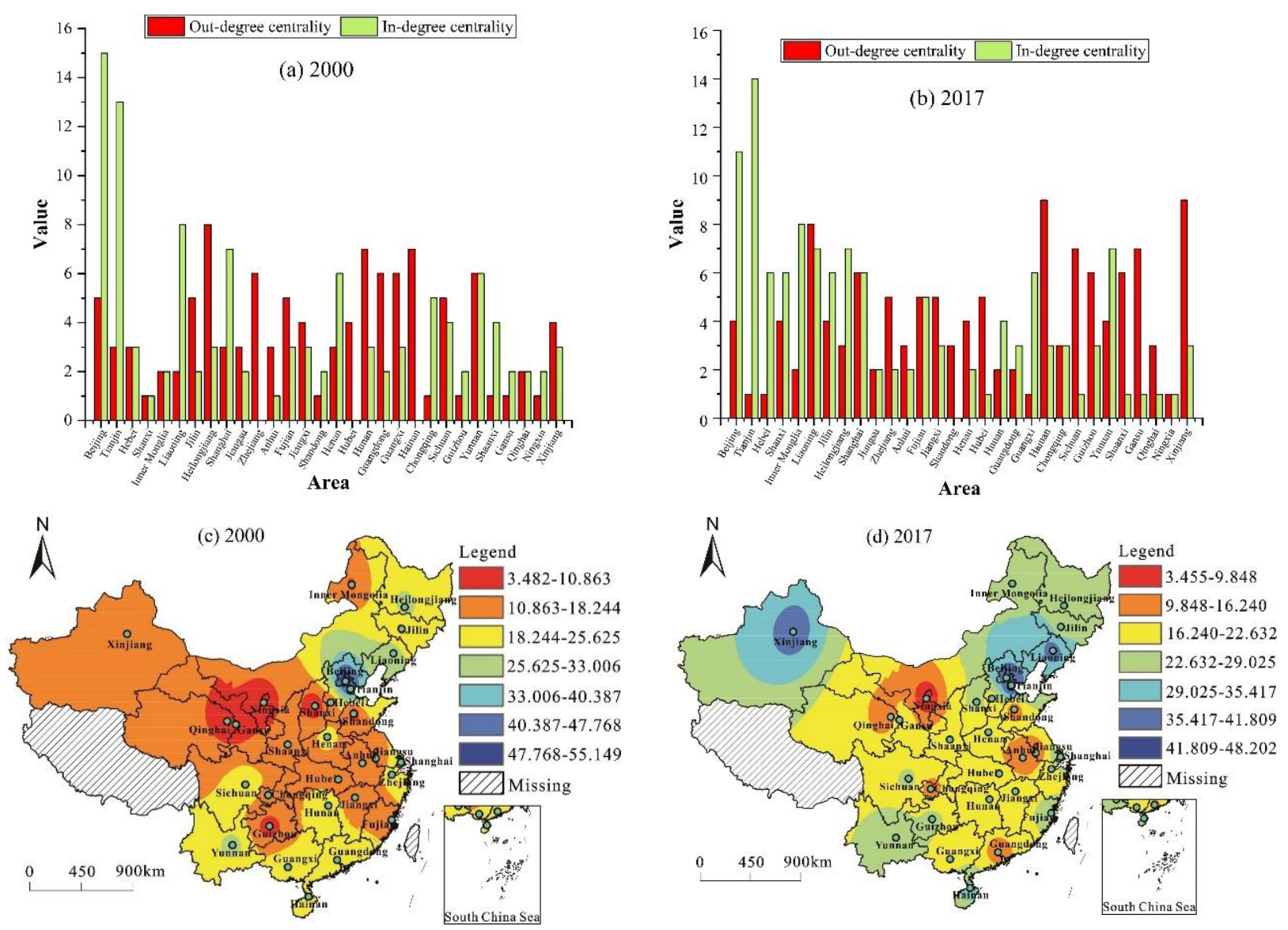

Figure 4. The spatial distribution of point degree in year $2000(\mathbf{a}, \mathbf{c})$ and $2017(\mathbf{b}, \mathbf{d})$.

\section{(1) Point Degree}

Out-degree centrality and in-degree centrality can reflect the interaction relationships among provinces in the spatial network structure of tourism eco-efficiency. Specifically, the out-degree centrality and the in-degree centrality represents the spillover effect and agglomeration effect from tourism eco-efficiency, respectively. The average values of indegree centrality and out-degree centrality, shown in Figure 4a,b, experienced an overall growth trend during the sample period, which indicated that the inflow and outflow of tourism eco-efficiency among provinces were strengthening constantly, and that the mutual connection of tourism eco-efficiency between provinces was strengthening. To be more specific, in 2000, there were 14 provinces with higher out-degree centrality than mean value, in which Heilongjiang, Hunan, Hainan, Guangxi, Guangdong, Zhejiang and Yunnan ranked TOP 7, while Ningxia, Gansu, Guizhou and other regions exhibited less spillover 
effect for other provinces. Moreover, there were nine provinces with above-average indegree centrality, with Beijing, Tianjin, Liaoning and Henan in the top tier, and Hubei, Hainan and Shanxi in the lowest tier. In contrast, the number of provinces that exhibited an above-average out-degree centrality dropped by two in 2017, with Hainan, Fujian, Jiangxi and Sichuan still remaining in the top ranks, whereas the number of provinces with above-average in-degree centrality increased to 12 , showing that China's provincial-scale tourism eco-efficiency network was more closely structured; the number of provinces that can receive other radiation effects is increasing, and the cooperation and exchanges among different provinces in low-carbon tourism technologies were also continuously strengthening.

In 2000 and 2017, the interval of point centrality was [3.482, 55.149] and [3.455, 48.202], respectively. The interval range of point centrality saw a narrow trend, indicating that the spatial differences of point centrality among various provinces witnessed a trend of constant balance. The spatial network structure of tourism eco-efficiency tended to be balanced; provinces increasingly played a core role. As can be seen from Figure $4 c, d$, the spatial distribution pattern of point centrality has been expanded from a high value area in 2000 (with Beijing and Tianjin as the core) to two high value areas in 2017 (with Beijing as the core of the Northern area around Bohai Sea and Urumqi as the core of the northern Xinjiang region). While the coverage of the low-value areas of point centrality has been shrinking, its spatial distribution pattern has been reduced from a continuous low-value area in 2000 (the continuous low-value area with the core of Urban Agglomeration along the Yellow River in Ningxia and the Lanzhou-Xining Urban Agglomeration) and three scattered-point areas with low-value (Shanxi, Shandong and Guizhou) to one low-value area in 2017 (the low-value area with the core of Urban Agglomeration along the Yellow River in Ningxia). Some of the provinces with high point centrality, such as Tianjin, were able to share modern low-carbon tourism technology and management experience with other provinces, and, thus, improve their point centrality by increasing out-degree centrality. Other provinces, such as Xinjiang, become the province with high point centrality in 2017, which was mainly due to the deep implementation of the Aid-Xinjiang program. Xinjiang can absorb the management experience of developing low-carbon tourism products, designing low-carbon tourism routes, establishing low-carbon tourism enterprise, and so on, which improved the point centrality by strengthening in-degree centrality.

\section{(2) Closeness Centrality}

In 2000 and 2017, the ranges of closeness centrality were $(32.957,64.430)$ and $(33.727$, $64.390)$, respectively. On the one hand, the overall provincial closeness centrality tended to increase. On the other hand, the regional differences of closeness centrality among provinces gradually contracted. This indicated that more provinces can make full use of the transmission effect of the spatial network structure, quickly generate spatial connections with other provinces, and play the role of "central actors" in the spatial network structure of tourism eco-efficiency. As shown in Figure 5, similar to the geographical distribution pattern of point centrality, the areas covered with high closeness centrality were mainly distributed around the northern part of the Bohai Sea with Beijing and Tianjin as the core; the low-value areas were mainly distributed along the urban agglomeration along the Yellow River in Ningxia. With the spatial association of the tourism eco-efficiency among the provinces increasing, the spatial scope of the high closeness centrality saw an expanding trend to a certain extent, while the coverage of the low closeness centrality was reduced to a certain extent. On the one hand, the low-value areas with the core of the urban agglomeration along the Yellow River in Ningxia were difficult to spill over into the surrounding provinces due to the behindhand low-carbon tourism technology. On the other hand, due to their unfavorable transport accessibility, it was difficult to connect with the provinces located in the Central area or the Eastern area. Therefore, it played the role of marginal actor in the spatial network structure of tourism eco-efficiency. 

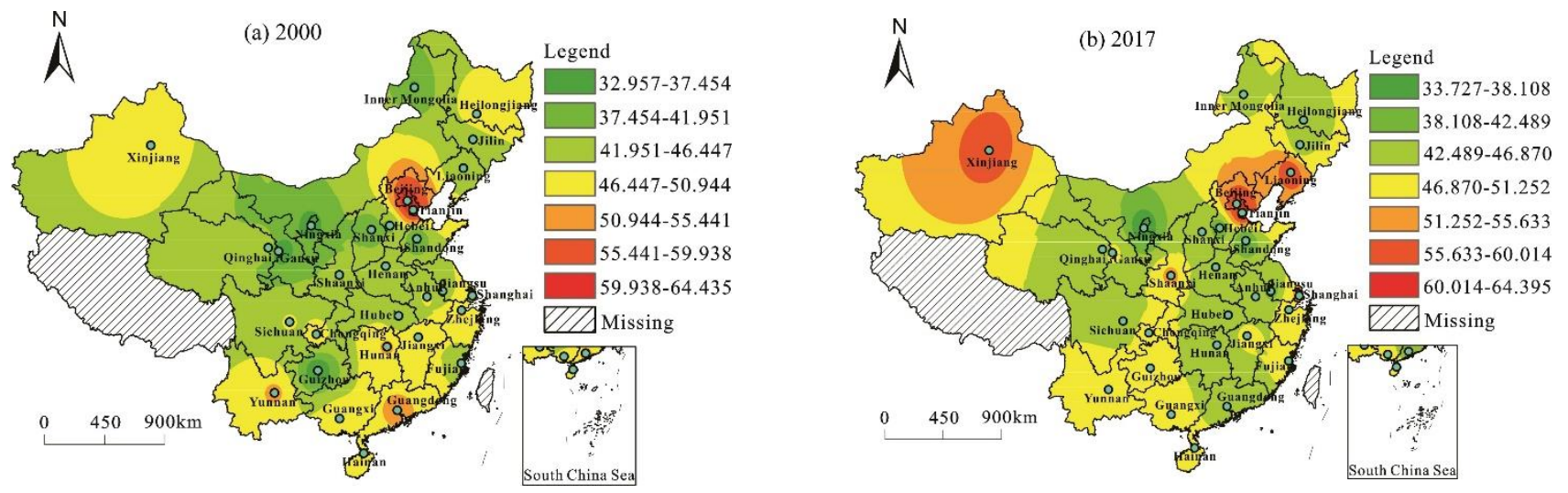

Figure 5. The spatial distribution of closeness centrality in year 2000 (a) and 2017 (b).

\section{(3) Betweenness Centrality}

The ranges of the provincial betweenness centrality were $(0,33.334)$ and $(0.001,25.612)$ in 2000 and 2017, respectively. The betweenness centrality saw a decreasing trend during the sample period, indicating that the spatial equilibrium of the betweenness centrality tended to be intensive, and the spatial network structure of tourism eco-efficiency gradually transformed from simple to complex (Figure 6). In 2000, the high-value areas of betweenness centrality were mainly located in Beijing, Tianjin, Guangdong, Hainan and Yunnan, which controlled at least two communication channels for tourism eco-efficiency, showing that the above-mentioned provinces played a role of bridge and intermediary in the transmission of low-carbon tourism technologies, and were the key nodes of the tourism eco-efficiency network structure. Significantly, some of the above provinces are provinces with a developed tourism economy in China, such as Beijing and Guangdong, which possess favorable low-carbon tourism technologies and management. Moreover, the other provinces were pilot low-carbon tourism provinces in China, such as Hainan and Yunnan, with a relatively perfect regulation of the tourism-related ecological environment; they can take on the role of intermediary to other provinces' tourism ecological protection resource elements.
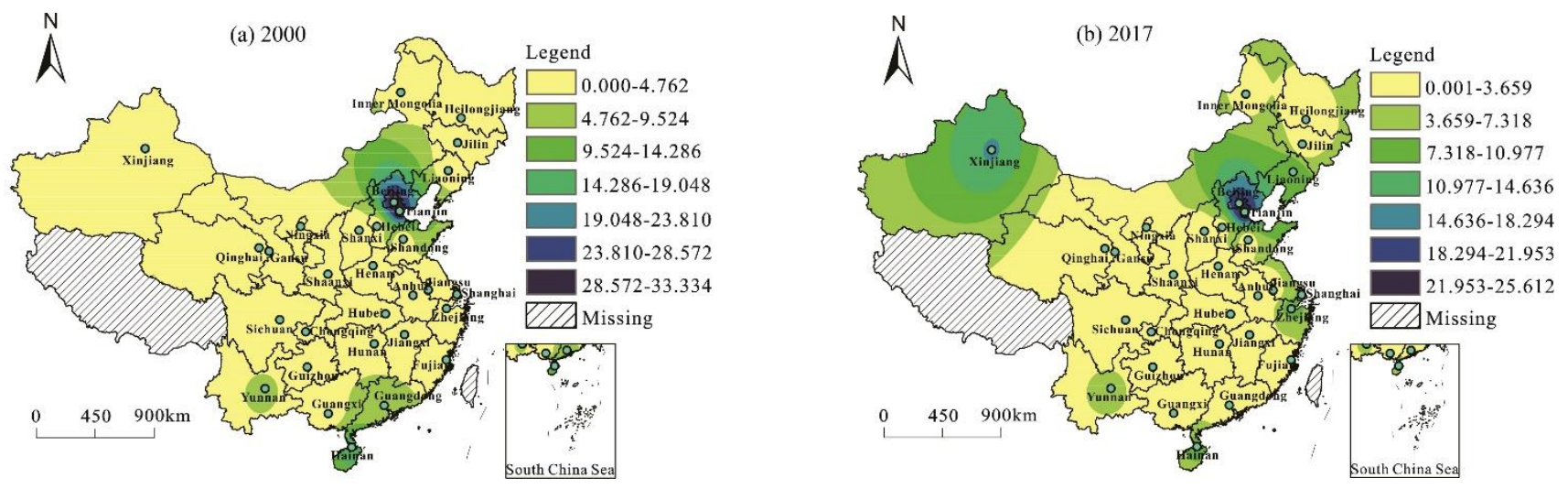

Figure 6. The spatial distribution of Betweenness centrality in year 2000 (a) and 2017 (b).

\subsection{Cohesive Sub-Group}

The convergent correlation (CONCOR) model in UCINET (University of California at Irvine Network) software was used for the cluster analysis. Figure 7 shows that the spatial network structure of tourism eco-efficiency in 2000 and 2017 was divided into four secondary sub-groups and eight tertiary sub-groups, forming multidimensional nested and fused spatial cliques and condensed subsets. The boundary of each sub-group faced with several obstacles due to the large number of sub-groups; the spatial connection and 
overflow of tourism eco-efficiency among provinces were not close. From the perspective of time evolution, the constituent provinces of each subgroup were constantly changing on the whole; however, the individual provinces under most sub-groups remained unchanged, such as Beijing and Hebei in the first sub-group, Hainan and Xinjiang in the seventh sub-group, and Qinghai, Ningxia and Gansu among the eighth sub-group, which fully demonstrated that the sub-groups of the spatial network structure of tourism eco-efficiency had gradually become stable, and the functions and roles of some provinces had not changed a lot, especially the eighth sub-group, except that Guizhou moved to other subgroups. Qinghai, Ningxia and Gansu provinces were always located in the eighth subgroup. These three provinces were mainly restricted by geographical location and held weak connections with other provinces; they were situated at the edge of the tourism eco-efficiency network.
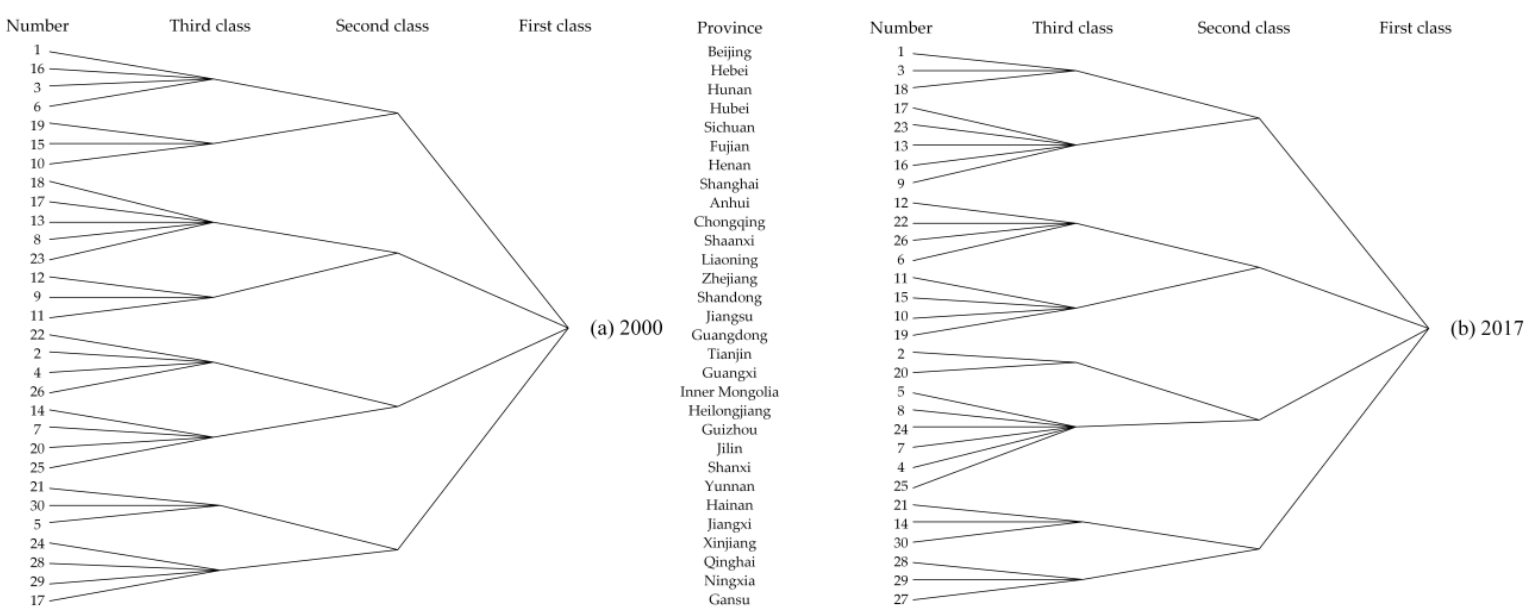

Figure 7. Subgroup of the tourism eco-efficiency network in China in year 2000 (a) and 2017 (b).

\section{Discussion and Conclusions}

\subsection{General Discussion}

Tourism eco-efficiency is an important indicator to assesses the degree of low-carbon development in the tourism industry. Additionally, the low-carbon development of the tourism industry is one of the most important goals of the high-quality development of tourism. Against the background of high-quality development, it is imperative that tourism eco-efficiency should be explored. Although increasing attention has been paid to tourism eco-efficiency, there is scant work on the spatial network structure of tourism ecoefficiency in China. Therefore, the practical background and theoretical gap have driven us to concentrate on this topic. This study adopted Super-SBM, considering undesired output and social network analysis to explore the evolution characteristics of spatial network structure of tourism eco-efficiency.

There was been a slight rise of tourism eco-efficiency in China; the order of spatial distribution characteristics by areas were Eastern, Northeastern, Central, and Western. From the perspective of a single province, tourism eco-efficiency of more than two thirds of the provinces presented an increasing trend, indicating that provinces have increasingly begun to pay more attention to the quality improvement of the tourism industry rather than solely to quantity growth [5]. More specifically, improving tourism eco-efficiency has been a crucial strategy that coordinates tourism-related economic development and eco-environmental protection in tourists' destinations in China [7,38].

There are significant spatial connections of tourism eco-efficiency among various provinces, which is in accordance with the findings of Wang, $\mathrm{Xia}$, Dong, $\mathrm{Li}, \mathrm{Li}, \mathrm{Ba}$ and Zhang [15]. In terms of overall network, although spatial connection of tourism ecoefficiency among various provinces has heightened during the sample period to a certain extent, the spatial network structure of tourism eco-efficiency was still loose and unstable. 
Moreover, there existed rigid stratification in the spillover relationship of tourism ecoefficiency among different provinces. More seriously, the above-mentioned phenomenon has not been profoundly changed. From the perspective of the small-world characteristic, there was a lack of cohesive force and connection convenience in spatial network structures of tourism eco-efficiency, demonstrating that it is imperative that the central government establish tourism eco-environmental protection and supervision mechanisms across provinces, which is in line with the conclusion of Sun, Hou, Huang and Zhong [7].

With regard to an individual network, the spatial network structure of tourism ecoefficiency has become more compact, complicated, and balanced, which demonstrates that, increasingly, provinces can rapidly generate connections between other provinces and play the role of intermediary in the spatial network structure of tourism eco-efficiency. Generally, due to the limitation of geographical location, provinces located in the Western area play a marginal role in the network structure, which results from the fact that there is a lack of modern low-carbon tourism technology, and not enough investment in environmental protection in the Western area [17]. With respect to the results of the cohesive group, there existed the multidimensional nested and fused spatial factions and condensed subsets in the spatial network structure of tourism eco-efficiency; however, there was a dearth of effective connection among second or third sub-groups, which further confirmed that the spatial network structure of tourism eco-efficiency was incompact.

\subsection{Theoretical Contributions}

Our study makes three contributions to the new body of knowledge. To our knowledge, our research may be among the first study efforts to explore the evolution characteristics of the spatial network structure of provincial-level tourism eco-efficiency. Firstly, the extant literature mainly concentrates on a single tourism sector, such as scenic spots and hotels; this study can enrich and broaden the literature about the tourism efficiency of all tourist destinations. Secondly, this study grasps the spatial relationship of tourism eco-efficiency among different tourist destinations based on the relational data, providing new research perspectives for other scholars who expect to investigate spatiotemporal characteristics of tourism eco-efficiency. Thirdly, our research constructs the spatial connection matrix of tourism eco-efficiency by using the modify gravity model. Although the empirical investigation takes 30 provinces of China as a case study, this model is universal and applicable across other countries.

\subsection{Practical Implications}

This conclusion of our research is of great significance to the sustainable development of the tourism industry in China. Based on these conclusions, this study put forward recommendations for destination management organizations (DMOs). First, the spatial differences of tourism eco-efficiency across four areas must be taken into account by the central government. More capital investment and policy support should be brought into the Central and Western areas by the implementation of the Western Development Strategy and Central Risen Strategy, thus, achieving the coordinated improvement of tourism ecoefficiency. Second, the spatial network structure of tourism eco-efficiency was still loose and unstable. Therefore, the spatial connection of tourism eco-efficiency must be strengthened by accelerating the flow of information and technology among different provinces. For example, Anhui Province can gain the spillover of technology and the radiation of management from the other provinces in Yangtze River Delta Urban Agglomeration. Third, the barrier of administrative division needs to be broken by combining macroeconomic regulation and market disposition, which aims to generate more channels of the communication regarding low-carbon development. Given that there was a dearth of connections of tourism eco-efficiency among the second or third sub-groups, the cooperation and connection of sustainable tourism development should also be optimized by the construction of a low-carbon tourism market and the decrease of connection cost. 


\subsection{Limitations and Future Research}

This study is not without limitations, which should not be overlooked; however, it also paves the potential road for future study. Firstly, with tourism-related economic development, the coefficients or the calculation method of carbon emissions from the tourism industry need to be adjusted in future research. Secondly, the data on the use of tourism land cannot be included in an input-output index system due to the size of the dataset. Therefore, the index system must be improved in future research. Thirdly, future scholars should explore the factors driving the spatial network structure of tourism eco-efficiency.

Author Contributions: Conceptualization, Q.L. and J.S.; methodology, T.D. and J.X.; formal analysis, Q.L. writing-original draft preparation, E.W. and J.L.; writing-review and editing, Q.L. and J.S. All authors have read and agreed to the published version of the manuscript.

Funding: This research was funded by The National Natural Science Foundation of China, grant number 42171170, 41801154, and 41901193. Meanwhile, The Chuzhou Science and Technology Plan Project, grant number 2021ZD007, and The Key University Science Research Project of Anhui Province, grant number KJ2021A1078 also provided supports for this study.

Institutional Review Board Statement: Not applicable.

Informed Consent Statement: Not applicable.

Data Availability Statement: Data available from the authors upon request.

Acknowledgments: We acknowledge the precious advice of the referees and editors. Meanwhile, we thank An Shi for his contribution that he modified all pictures.

Conflicts of Interest: The authors declare no conflict of interest.

\section{Appendix A}

Evaluation on Carbon Dioxide Emission and Energy Consumption from the Tourism Industry

Based on the existing results at home and abroad, this study chose to use the "bottomup" method to calculate energy consumption and carbon dioxide emissions from the tourism industry. This study calculated the energy consumption/carbon dioxide emissions in three key tourism sectors, namely tourism transportation, tourism accommodation and tourism activities, and then summarized the total energy consumption/carbon dioxide emissions. The calculation formula is as follows:

$$
C^{t}=\sum_{j=1}^{3} C_{j}^{t}=C_{1}^{t}+C_{2}^{t}+C_{3}^{t}
$$

where, $C^{t}$ represents the total energy consumption/carbon dioxide emissions of tourism industry in year $t ; C_{j}^{t}$ represents the energy consumption/carbon dioxide emissions of department $j$ in year $t ; C_{1}^{t}$ represents energy consumption/carbon dioxide emissions of tourism and transportation sectors in year $t ; C_{2}^{t}$ represents energy consumption/carbon dioxide emissions of tourism and accommodation sector in year $t ; C_{3}^{t}$ represents energy consumption/carbon dioxide emissions from tourism activities in year $t$.

$$
C_{1}^{t}=\sum_{i=1}^{30} C_{i 1}^{t}=\sum_{i=1}^{30} \sum_{x=1}^{4} Q_{i x}^{t} \cdot f_{x} \cdot \alpha_{x}
$$

where, $C_{i 1}^{t}$ represents the energy consumption/carbon dioxide emissions of tourism and transportation sectors in region $i$ in year $t ; Q_{i x}^{t}$ represents the passenger turnover of category $x$ mode of transportation in region $i$ in year $t ; f_{x}$ represents the proportion of tourists in the passenger traffic volume of class $x$ mode. The values of highway, civil aviation, railway and water transportation can be determined as $13.8 \%, 64.7 \%, 31.6 \%$, and $10.6 \%$, respectively, by referring to the existing research results. $\alpha_{x}$ represents the energy consumption/carbon 
dioxide emissions coefficient of class $x$ transportation mode, where the $\alpha$ value of highway is $133 \mathrm{~g} \mathrm{CO}_{2} / \mathrm{pkm}$, the value of civil aviation is $137 \mathrm{~g} \mathrm{CO}_{2} / \mathrm{pkm}$, and the railway and water transport are $27 \mathrm{~g} \mathrm{CO}_{2} / \mathrm{pkm}$ and $106 \mathrm{~g} \mathrm{CO}_{2} / \mathrm{pkm}$.

$$
C_{2}^{t}=\sum_{i=1}^{30} C_{i 2}^{t}=\sum_{i=1}^{30} N_{i}^{t} \cdot l_{i}^{t} \cdot \beta
$$

where, $C_{i 2}^{t}$ represents the energy consumption/carbon dioxide emissions of the tourism and accommodation sector in region $i$ in year $t ; N_{i}^{t}$ is the number of beds in tourist hotels in region $i$ in year $t ; l_{i}^{t}$ represents the average room occupancy rate in region $i$ in year $t ; \beta$ is the energy consumption/carbon dioxide emissions coefficient ( $g / p$ visitor-night) per bed per night, and the value is $2.458 \mathrm{~g} / \mathrm{p}$ visitor-night.

$$
C_{3}^{t}=\sum_{i=1}^{30} C_{i 3}^{t}=\sum_{i=1}^{30} \sum_{s=1}^{5} P_{i s}^{t} \cdot \gamma_{s}
$$

where, $C_{i 3}^{t}$ represents the energy consumption/carbon dioxide emissions of regional tourism activities in year $t$; $P_{i S}^{t}$ denotes the number of tourists participating in category $s$ tourism activities in region $i$ in year $t ; \gamma_{S}$ is the energy consumption/carbon dioxide emissions coefficient of class $s$ tourism activities, and the energy consumption/carbon dioxide emissions coefficient of tourism, vacation tourism, business trip, visiting friends and relatives and other tourism activities are, respectively, $417 \mathrm{~g} / \mathrm{p}$ visitor, $1670 \mathrm{~g} / \mathrm{p}$ visitor, $786 \mathrm{~g} / \mathrm{p}$ visitor, $591 \mathrm{~g} / \mathrm{p}$ visitor and $172 \mathrm{~g} / \mathrm{p}$ visitor.

\section{References}

1. Wang, Z.; Liu, Q.; Xu, J.; Fujiki, Y. Evolution characteristics of the spatial network structure of tourism efficiency in China: A province-level analysis. J. Destin. Mark. Manag. 2020, 18, 100509. [CrossRef]

2. Sun, Y.; Hou, G. Analysis on the Spatial-Temporal Evolution Characteristics and Spatial Network Structure of Tourism EcoEfficiency in the Yangtze River Delta Urban Agglomeration. Int. J. Environ. Res. Public Health 2021, 18, 2577. [CrossRef] [PubMed]

3. Scott, D.; Peeters, P.; Gössling, S. Can tourism deliver its "aspirational” greenhouse gas emission reduction targets? J. Sustain. Tour. 2010, 18, 393-408. [CrossRef]

4. Peng, H.; Zhang, J.; Lu, L.; Tang, G.; Yan, B.; Xiao, X.; Han, Y. Eco-efficiency and its determinants at a tourism destination: A case study of Huangshan National Park, China. Tour. Manag. 2017, 60, 201-211. [CrossRef]

5. Liu, J.; Zhang, J.; Fu, Z. Tourism eco-efficiency of Chinese coastal cities-Analysis based on the DEA-Tobit model. Ocean. Coast. Manag. 2017, 148, 164-170. [CrossRef]

6. Gössling, S.; Peeters, P.; Ceron, J.-P.; Dubois, G.; Patterson, T.; Richardson, R.B. The eco-efficiency of tourism. Ecol. Econ. 2005, 54, 417-434. [CrossRef]

7. Sun, Y.; Hou, G.; Huang, Z.; Zhong, Y. Spatial-Temporal Differences and Influencing Factors of Tourism Eco-Efficiency in China's Three Major Urban Agglomerations Based on the Super-EBM Model. Sustainability 2020, 12, 4156. [CrossRef]

8. Gössling, S.; Broderick, J.; Upham, P.; Ceron, J.-P.; Dubois, G.; Peeters, P.; Strasdas, W. Voluntary Carbon Offsetting Schemes for Aviation: Efficiency, Credibility and Sustainable Tourism. J. Sustain. Tour. 2007, 15, 223-248. [CrossRef]

9. Perch-Nielsen, S.; Sesartic, A.; Stucki, M. The greenhouse gas intensity of the tourism sector: The case of Switzerland. Environ. Sci. Policy 2010, 13, 131-140. [CrossRef]

10. Yu, L.; Bai, Y.; Liu, J. The dynamics of tourism's carbon footprint in Beijing, China. J. Sustain. Tour. 2019, 27, 1553-1571. [CrossRef]

11. Lin, L. Research on the spatio-temporal evolution of tourism eco-efficiency by using the ecological footprint model. Fresenius Environ. Bull. 2021, 30, 10665-10674.

12. Yang, G.; Li, P.; Zheng, B.; Zhang, Y. GHG Emission-Based Eco-Efficiency Study on Tourism Itinerary Products in Shangri-La, Yunnan Province, China. Curr. Issues Tour. 2008, 11, 604-622. [CrossRef]

13. Zha, J.; Yuan, W.; Dai, J.; Tan, T.; He, L. Eco-efficiency, eco-productivity and tourism growth in China: A non-convex metafrontier DEA-based decomposition model. J. Sustain. Tour. 2020, 28, 663-685. [CrossRef]

14. Zha, J.; He, L.; Liu, Y.; Shao, Y. Evaluation on development efficiency of low-carbon tourism economy: A case study of Hubei Province, China. Socio-Econ. Plan. Sci. 2019, 66, 47-57. [CrossRef]

15. Wang, R.; Xia, B.; Dong, S.; Li, Y.; Li, Z.; Ba, D.; Zhang, W. Research on the Spatial Differentiation and Driving Forces of Eco-Efficiency of Regional Tourism in China. Sustainability 2020, 13, 280. [CrossRef] 
16. Lu, F.; Qin, W.; Wang, Y.-X.; Gupta, P. Research on Spatial Pattern Dynamic Evolution Algorithm and Optimization Model Construction and Driving Mechanism of Provincial Tourism Eco-Efficiency in China under the Background of Cloud Computing. Sci. Program. 2021, 2021, 1951264. [CrossRef]

17. Qiu, X.; Fang, Y.; Yang, X.; Zhu, F. Tourism Eco-Efficiency Measurement, Characteristics, and Its Influence Factors in China. Sustainability 2017, 9, 1634. [CrossRef]

18. Pan, F.; Hall, S.; Zhang, H. The spatial dynamics of financial activities in Beijing: Agglomeration economies and urban planning. Urban Geogr. 2020, 41, 849-864. [CrossRef]

19. Li, B.; Ma, X.; Chen, K. Eco-efficiency measurement and spatial-temporal evolution of forest tourism. Arab. J. Geosci. 2021, 14, 568. [CrossRef]

20. Su, L.; Ji, X. Spatial-temporal differences and evolution of eco-efficiency in China's forest park. Urban For. Urban Green. 2021, 57, 126894. [CrossRef]

21. Nurmatov, R.; Fernandez Lopez, X.L.; Coto Millan, P.P. Tourism, hospitality, and DEA: Where do we come from and where do we go? Int. J. Hosp. Manag. 2021, 95, 102883. [CrossRef]

22. Tone, K. A slacks-based measure of efficiency in data envelopment analysis. Eur. J. Oper. Res. 2001, 130, 498-509. [CrossRef]

23. Zhang, J.; Su, Y.; Wu, J.; Liang, H. GIS based land suitability assessment for tobacco production using AHP and fuzzy set in Shandong province of China. Comput. Electron. Agric. 2015, 114, 202-211. [CrossRef]

24. Tone, K. Dealing with Undesirable Outputs in DEA: A Slacks-based Measure (SBM) Approach. GRIPS Res. Rep. Ser. 2003, 2003, $44-45$.

25. Bai, C.; Zhou, L.; Xia, M.; Feng, C. Analysis of the spatial association network structure of China's transportation carbon emissions and its driving factors. J. Environ. Manag. 2020, 253, 109765. [CrossRef] [PubMed]

26. He, Y.-Y.; Wei, Z.-X.; Liu, G.-Q.; Zhou, P. Spatial network analysis of carbon emissions from the electricity sector in China. J. Clean. Prod. 2020, 262, 121193. [CrossRef]

27. Shen, W.; Liang, H.; Dong, L.; Ren, J.; Wang, G. Synergistic $\mathrm{CO}_{2}$ reduction effects in Chinese urban agglomerations: Perspectives from social network analysis. Sci. Total Environ. 2021, 798, 149352. [CrossRef]

28. Gan, C.; Voda, M.; Wang, K.; Chen, L.; Ye, J. Spatial network structure of the tourism economy in urban agglomeration: A social network analysis. J. Hosp. Tour. Manag. 2021, 47, 124-133. [CrossRef]

29. Pierce, P.P.; Kabo, F.; Killian, J.; Stucky, C.; Huffman, S.; Migliore, L.; Braun, L. Social network analysis: Exploring connections to advance military nursing science. Nurs. Outlook 2021, 69, 311-321. [CrossRef]

30. Yao, Q.; Li, R.Y.M.; Song, L.; Crabbe, M.J.C. Construction safety knowledge sharing on Twitter: A social network analysis. Saf. Sci. 2021, 143, 105411. [CrossRef]

31. Dai, L.; Derudder, B.; Liu, X. The evolving structure of the Southeast Asian air transport network through the lens of complex networks, 1979-2012. J. Transp. Geogr. 2018, 68, 67-77. [CrossRef] [PubMed]

32. Zhang, P.; Zhao, Y.; Zhu, X.; Cai, Z.; Xu, J.; Shi, S. Spatial structure of urban agglomeration under the impact of high-speed railway construction: Based on the social network analysis. Sustain. Cities Soc. 2020, 62, 102404. [CrossRef]

33. Song, M.; Li, H. Estimating the efficiency of a sustainable Chinese tourism industry using bootstrap technology rectification. Technol. Forecast. Soc. Chang. 2019, 143, 45-54. [CrossRef]

34. Chaabouni, S. China's regional tourism efficiency: A two-stage double bootstrap data envelopment analysis. J. Destin. Mark. Manag. 2019, 11, 183-191. [CrossRef]

35. Castilho, D.; Fuinhas, J.A.; Marques, A.C. The impacts of the tourism sector on the eco-efficiency of the Latin American and Caribbean countries. Socio-Econ. Plan. Sci. 2021, 78, 101089. [CrossRef]

36. Wu, P.; Shi, P.H. An estimation of energy consumption and $\mathrm{CO}_{2}$ emissions in tourism sector of China. J. Geogr. Sci. 2011, 21, 733-745. [CrossRef]

37. Wu, P.; Han, Y.; Tian, M. The measurement and comparative study of carbon dioxide emissions from tourism in typical provinces in China. Acta Ecol. Sin. 2015, 35, 184-190. [CrossRef]

38. He, L.; Zha, J.; Loo, H.A. How to improve tourism energy efficiency to achieve sustainable tourism: Evidence from China. Curr. Issues Tour. 2019, 23, 1-16. [CrossRef] 